\title{
Priming with inflammatory cytokines is not a prerequisite to increase immune- suppressive effects and responsiveness of equine amniotic mesenchymal stromal cells
}

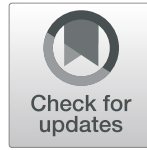

\author{
Anna Lange-Consiglio ${ }^{1 *}$ (D) Pietro Romele ${ }^{2}$, Marta Magatti ${ }^{2}$, Antonietta Silini ${ }^{2}$, Antonella Idda', \\ Nicola Antonio Martino ${ }^{3}$, Fausto Cremonesi ${ }^{1}$ and Ornella Parolini ${ }^{2,4}$
}

\begin{abstract}
Background: Equine amniotic mesenchymal stromal cells (AMSCs) and their conditioned medium (CM) were evaluated for their ability to inhibit in vitro proliferation of peripheral blood mononuclear cells (PBMCs) with and without priming. Additionally, AMSC immunogenicity was assessed by expression of $\mathrm{MHCl}$ and $\mathrm{MHCll}$ and their ability to counteract the in vitro inflammatory process.

Methods: Horse PBMC proliferation was induced with phytohemagglutinin. AMSC priming was performed with 10 $\mathrm{ng} / \mathrm{ml}$ of TNF-a, $100 \mathrm{ng} / \mathrm{ml}$ of IFN- $\gamma$, and a combination of $5 \mathrm{ng} / \mathrm{ml}$ of TNF- $\alpha$ and $50 \mathrm{ng} / \mathrm{ml}$ of IFN- $\gamma$.

The CM generated from naïve unprimed and primed AMSCs was also tested to evaluate its effects on equine endometrial cells in an in vitro inflammatory model induced by LPS. Immunogenicity marker expression $(\mathrm{MHCl}$ and II) was evaluated by qRT-PCR and by flow cytometry.

Results: Priming does not increase $\mathrm{MHCl}$ and II expression. Furthermore, the inhibition of PBMC proliferation was comparable between naive and conditioned cells, with the exception of AMSCs primed with both TNF- $a$ and IFN- $\gamma$ that had a reduced capacity to inhibit T cell proliferation. However, AMSC viability was lower after priming than under other experimental conditions. CM from naïve and primed AMSCs strongly inhibited PBMC proliferation and counteracted the inflammatory process, rescuing about $65 \%$ of endometrial cells treated by LPS.
\end{abstract}

Conclusion: AMSCs and their CM have a strong capacity to inhibit PBMC proliferation, and priming is not necessary to improve their immunosuppressive activity or reactivity in an inflammatory in vitro model.

Keywords: Equine, Amniotic stromal-derived cells, PBMC proliferation, Priming, Pro-inflammatory cytokines

\section{Background}

Mesenchymal stromal cells (MSCs) have important properties of self-renewal, high proliferation, and differentiation potential, as well as their immunomodulatory features. They are a heterogeneous cell population found

\footnotetext{
*Correspondence: anna.langeconsiglio@unimi.it

'Department of Veterinary Medicine (DIMEVET), Università degli Studi di Milano, Via dell'Università 6, 26900 Lodi, Italy

Full list of author information is available at the end of the article
}

in the stroma of various adult, fetal, and extra-fetal tissues where they act as progenitor cells during natural tissue turnover. Extra-fetal tissues such as the umbilical cord, amniotic fluid, amnion, and placenta do not come with the ethical issues related to embryonic cells nor require invasive procedures involved in bone marrow harvesting. In addition, MSCs share the general properties of MSCs and, in some cases, have more potent immunomodulatory properties than adult counterparts $[1,2]$.

C C The Author(s). 2020 Open Access This article is licensed under a Creative Commons Attribution 4.0 International License, which permits use, sharing, adaptation, distribution and reproduction in any medium or format, as long as you give appropriate credit to the original author(s) and the source, provide a link to the Creative Commons licence, and indicate if changes were made. The images or other third party material in this article are included in the article's Creative Commons licence, unless indicated otherwise in a credit line to the material. If material is not included in the article's Creative Commons licence and your intended use is not permitted by statutory regulation or exceeds the permitted use, you will need to obtain permission directly from the copyright holder. To view a copy of this licence, visit http://creativecommons.org/licenses/by/4.0/ The Creative Commons Public Domain Dedication waiver (http://creativecommons.org/publicdomain/zero/1.0/) applies to the data made available in this article, unless otherwise stated in a credit line to the data. 
Immunomodulation is a regulatory activity by which MSCs interact with the adaptive and innate immune cells [3], both in cell-to-cell contact and via paracrine signaling, with the potential either to drive the inflammatory response toward its resolution or to strengthen it, depending on the surrounding microenvironment [4]. This property was first described by Bartholomew et al. [5], who reported the ability of MSCs to suppress lymphocyte proliferation in vitro and prevent rejection of in vivo allograft.

According to the polarization paradigm, quiescent MSCs do not possess immunomodulatory properties [6] and naïve MSCs can be polarized by environmental stimuli to acquire a pro-inflammatory (MSC1) or an immunosuppressive (MSC2) phenotype [7]. This switch is activated via Toll-like receptor family (TLR) members, respectively, by TLR4 and TLR3, which act upon recognition of pathogen-associated molecular patterns [8]. However, the inflammatory microenvironment is rich in other molecules that can prompt MSC activation such as those released by immune cells after tissue degradation. The inflammatory cytokine milieu plays a pivotal role in the switch of the MSC phenotype by determining functional maturation $[4,9]$. Thus, active MSCs release cytokines, chemokines, growth factors, and microvesicles that act in a feedback loop to control the inflammatory response [10]. The damaged tissue is characterized, in vivo, by the presence of inflammatory cytokines that prime MSCs, acting as a sub-lethal event that can trigger an adaptive response of MSCs to future injury or damage [11]. However, the damaged tissue is also an inhospitable environment that can lead to the premature death of MSCs used for therapy [12] and to an increase in their immunogenicity [13].

In this context, MSC activation in vitro, defined also as priming or licensing, seems to be required to improve the survival rate of transplanted cells and to induce, simultaneously, the development of an immunosuppressive activity. Indeed, several studies indicate that MSCs need to be licensed by inflammatory stimuli, such as tumor necrosis factor- $\alpha$ (TNF- $\alpha)$, interferon- $\gamma$ (IFN- $\gamma$ ), and interleukin-1 $\alpha / \beta$, to exert or improve their immunosuppressive actions [14]. Thus, in recent years, several studies have evaluated whether preconditioning bone marrow-derived MSCs cultured in vitro with IFN- $\gamma$ and TNF- $\alpha$ could elicit a stronger immunosuppressive activity $[4,15-17]$. IFN $-\gamma$ induces a transient expression of indoleamine-2,3 dioxygenase (IDO) which inhibits $\mathrm{T}$ cell activation, proliferation, and functionality due to L-tryptophane depletion [9]. In addition, IFN- $\gamma$ priming induces the production of immunomodulatory molecules such as prostaglandin-E2 (PGE2), hepatocyte growth factor (HGF), transforming growth factor $\beta 1$ (TGF- $\beta 1$ ), and $\mathrm{C}-\mathrm{C}$ motif chemokine ligand 2 (CCL2). Preconditioning with TNF- $\alpha$ has also been shown to enhance the production and release of these molecules, although to a lesser extent than IFN- $\gamma$ priming. Bone marrow MSCs primed with a combination of IFN- $\gamma$ and TNF- $\alpha$ had an even stronger immunosuppressive phenotype compared to those primed with a single factor, although significant differences were observed in the inhibitory potential of MSCs based on donor source [16]. However, priming with IFN- $\gamma$ amplifies the expression of $M H C I$ and MHCII in equine bone marrow-derived cells [18] increasing their immunogenicity.

We have previously reported that naive amniotic mesenchymal stromal cells (AMSCs) from horse term placentae inhibit the proliferation of peripheral blood mononuclear cells (PBMCs) in vitro in both cell-cell contact and in a transwell culture system [19] without priming.

The aim of this paper is to understand if priming equine AMSCs in vitro with inflammatory cytokines improves their in vitro capability to inhibit PBMC proliferation and, eventually, alters their immunogenicity (expression of MHCI and MHCII markers). To this aim, AMSCs were stimulated by TNF- $\alpha$ and IFN- $\gamma$, molecules known to be present in inflammatory environments [20]. Since MSCs act via paracrine signaling, the CM generated from naïve and from primed AMSCs was also tested on equine endometrial cells in an inflammatory in vitro model to evaluate if priming makes the secretome more responsive in its reparative effect.

\section{Materials and methods Study design}

The first part of the study evaluated the effect of AMSC priming with pro-inflammatory cytokines (TNF- $\alpha$, IFN$\gamma$, and their combination) on the expression of immunogenicity markers as well as MHCI and MHCII. The second part investigated the effect of naïve and primed AMSC, and their CM, on lymphocyte proliferation. The third part of the study evaluated the in vitro effect of $\mathrm{CM}$ derived from naïve (CM-CTR) and from primed AMSCs on endometrial cells treated with lipopolysaccharide (LPS). The cell viability, the apoptotic index, and the bioenergetic/oxidative status, expressed as mitochondria activity and intracellular sources of reactive oxygen species (ROS) levels, were determined.

The study was performed on AMSCs obtained from three distinct amniotic membranes (donors).

\section{Materials}

Equine term placentas ( $\left.n \_3\right)$ were obtained following spontaneous vaginal delivery. All procedures to collect allanto-amniotic membranes were conducted following the standard veterinary practice and in accordance with the 2010/63 European Union directive on animal 
protection and Italian Law (D.L. No. 116/1992). Written informed consent from the owners was also obtained to collect placentas at delivery. Equine blood collection was approved by the University of Milan Ethics Committee (Protocol Number 41/15), and informed owner consent was obtained.

Uteri samples were collected from horses slaughtered in a national slaughterhouse under legal regulation.

Chemicals were obtained from Sigma-Aldrich Chemical (Milan, Italy) unless otherwise specified. LPS was purchased by Sigma-Aldrich Chemical (Escherichia coli 0:111B4; L2630 catalog number). Equine recombinant IFN- $\gamma$ and equine recombinant TNF- $\alpha$ were purchased by R\&D System (MN, USA). Tissue culture plastic dishes were purchased from Euroclone (Milan, Italy).

\section{Amniotic membrane collection and cell isolation}

Allanto-amniotic membranes were obtained at the term from normal pregnancies of three horses and were processed separately as described by Lange Consiglio et al. [21]. First, the amniotic membrane was separated from its juxtaposed allantois and cut into small pieces (about $9 \mathrm{~cm}^{2}$ each). The amnion fragments underwent an incubation step with $2.4 \mathrm{U} / \mathrm{ml}$ dispase (Becton Dickinson, Milan, Italy) in phosphate buffer solution (PBS) for 9 $\min$ at $38.5^{\circ} \mathrm{C}$. Before completing the enzymatic digestion, the fragments were kept in high-glucose Dulbecco's modified Eagle's medium (HG-DMEM; EuroClone, Milan, Italy), supplemented with $10 \%$ heat-inactivated fetal bovine serum (FBS) and $2 \mathrm{mM} \mathrm{L}$-glutamine for 5$10 \mathrm{~min}$ at room temperature. Final fragment digestion was achieved with $0.93 \mathrm{mg} / \mathrm{ml}$ collagenase type I and 20 $\mathrm{mg} / \mathrm{ml}$ DNAse (Roche, Mannheim, Germany) for approximately $3 \mathrm{~h}$ at $38.5^{\circ} \mathrm{C}$. The debris was removed using a $100-\mu \mathrm{m}$ cell strainer, and mobilized cells were collected by centrifugation at $200 \times g$ for $10 \mathrm{~min}$. The AMSCs were cultured in HG-DMEM supplemented with $10 \% \mathrm{FBS}$, penicillin $(100 \mathrm{UI} / \mathrm{ml})$-streptomycin $(100$ $\mathrm{mg} / \mathrm{ml}), 0.25 \mathrm{mg} / \mathrm{ml}$ amphotericin $\mathrm{B}, 2 \mathrm{mM} \mathrm{L}$-glutamine, and $10 \mathrm{ng} / \mathrm{ml}$ epidermal growth factor until passage 3 .

\section{Endometrial cell isolation}

Fresh uteri were collected from three different mares at the slaughterhouse intended for human consumption and unrelated to our studies. Samples were obtained from healthy normal-cycling mares in diestrus (middlelate luteal phase). Only uteri from mares with an obvious corpus luteum on the ovary were used for endometrial fragment collection and ensuing cell culture.

Endometrial cells from diestrus mare uteri were obtained according to the protocol described by Donofrio et al. [22] and slightly modified for equine cells. Briefly, the endometrium was digested in sterile-filtered Hank's buffered salt solution supplemented with $2 \mathrm{mg} / \mathrm{ml}$ collagenase II, $4 \mathrm{mg} / \mathrm{ml}$ bovine serum albumin, and 0.4 $\mathrm{mg} / \mathrm{ml} \mathrm{DNase} \mathrm{I} \mathrm{for} 90 \mathrm{~min}$ at $38.5^{\circ} \mathrm{C}$ in a shaking bath. Cells were then filtered through a membrane with a pore size of $80 \mu \mathrm{m}$, centrifuged at $200 \times g$ for $10 \mathrm{~min}$, and then washed twice in PBS. This protocol allowed isolation of the endometrial stromal portion. Endometrial cell culture was established in HG-DMEM supplemented with $10 \% \mathrm{FBS}$, penicillin $(100 \mathrm{UI} / \mathrm{ml})$, streptomycin $(100 \mu \mathrm{g} /$ $\mathrm{ml}), 0.25 \mu \mathrm{g} / \mathrm{ml}$ amphotericin $\mathrm{B}$, and $2 \mathrm{mM}$ L-glutamine.

\section{Characterization by reverse transcription-PCR analysis of amniotic and endometrial cells}

Some mesenchymal (CD29, CD44, CD105, CD166) and hematopoietic (CD34) markers were evaluated by RTPCR analysis on AMSCs at P3. Equine-specific oligonucleotide primers and conventional PCR were used for the standard characterization of these cells as reported by Lange-Consiglio et al. [21]. Specific endometrial genes, such as progesterone receptor (PR), membraneassociated progesterone receptor (MPR), membranebound intracellular progesterone receptor component 1 (PGRMC1), and homeobox protein Hox-A9-like (HOXA-9), were analyzed on endometrial cells immediately after their isolation as reported by Corradetti et al. [23]. GAPDH was employed as reference gene.

\section{Priming with pro-inflammatory cytokines}

Equine AMSCs were seeded at a density of $3 \times 10^{3}$ on 12 well plates and stimulated for $96 \mathrm{~h}$ at $38.5^{\circ} \mathrm{C}$ in $5 \%$ of $\mathrm{CO}_{2}$ with $10 \mathrm{ng} / \mathrm{ml}$ of TNF- $\alpha, 100 \mathrm{ng} / \mathrm{ml}$ of IFN- $\gamma$, as described for priming of equine BM-MSCs [18], and a combination of $5 \mathrm{ng} / \mathrm{ml}$ of TNF- $\alpha$ and $50 \mathrm{ng} / \mathrm{ml}$ of IFN- $\gamma$.

\section{Conditioned medium production and collection}

Conditioned medium (CM) from naïve (control, CMAMSC) and primed cells was obtained by culturing AMSCs at passage 3 in ultra-culture serum-free medium (Lonza, Basel, CH), without antibiotics for $96 \mathrm{~h}$ without replacement of medium.

Supernatants from each condition (CM-AMSC, CMAMSC-TNF- $\alpha, \quad$ CM-AMSC-IFN- $\gamma, \quad$ CM-AMSC-TNF$\alpha+$ IFN $-\gamma$ ) were collected, centrifuged at $700 \times g$ to remove cellular debris and stored at $-80^{\circ} \mathrm{C}$. No further centrifugations or filtrations were performed on $\mathrm{CM}$ to preserve its total composition in terms of soluble (growth factors, chemokines, and other molecules) and non-soluble factors such as extra-cellular vesicles. This procedure was performed for cells obtained from three different placentas.

The collected supernatants were lyophilized and stored at $4{ }^{\circ} \mathrm{C}$ until use, at which point they were diluted in sterile water to one quarter of the initial volume.

After collection of CM, adherent cells were detached with $0.05 \%$ trypsin-EDTA (ethylenediaminetetraacetic 
acid) and frozen in HG-DMEM supplemented with 90\% FBS and 10\% DMSO (dimethyl sulfoxide) in liquid nitrogen until gene expression analysis and lymphocyte proliferation tests were carried out.

\section{Gene expression of immunogenicity markers}

The mRNA expression levels of $M H C I$ and $M H C I I$ were measured in three biological replicates. According to the manufacturer protocol, total RNA was isolated using the mirVana $^{\text {ma }}$ miRNA isolation Kit (Life Technologies) and stored at $-20{ }^{\circ} \mathrm{C}$. The concentration and purity of RNAs were evaluated three times by the NanoQuant spectrophotometer (Thermo Scientific, USA). Eight samples, randomly chosen, were analyzed on Bioanalyzer 2100 using the Agilent RNA 6000 Pico Kit (Agilent) to verify the integrity of extracted RNA. According to the RNA quantity, each sample was normalized to the final RNA concentration of $10 \mathrm{ng} / \mathrm{ul}$.

RT-PCRs were performed with the high capacity cDNA Reverse Trascription Kit (Applied Biosystems/Life Technologies, Carlsbad, CA, USA) using 100 ng of RNA per reaction.

The qPCR experiments were run in triplicates (technical replicates) using the qPCR protocol described by TaqMan Fast Gene Expression Assays (Life Tecnologies $\left.{ }^{\mathrm{Tw}}\right)$ on 7500 Fast Real-time PCR System instrument (Applied Biosystems by Life Technologies ${ }^{\mathrm{Tm}}$ ). Each target gene was amplified to assess gene expression. The glyceraldehyde 3-phosphate dehydrogenase gene $(G A P D H)$ was the housekeeping control gene. The open-source PerlPrimer software v.1.1.17 was used to design equine-specific oligonucleotide primers based on available NCBI Equus caballus sequences or on mammal multi-aligned sequences. Primers were designed across an exon-exon junction in order to avoid DNA amplification (Table 1). The average target gene threshold cycle $\left(\Delta \mathrm{Ct}_{\mathrm{g}}\right)$ for each sample (calculated using the CT values of the technical replicates within each experimental condition) was normalized to the average GAPDH values $\left(\Delta \mathrm{Ct}_{\mathrm{GAPDH}}\right)$ of the same cDNA sample. Then, the expression variations calculated were normalized to internal control (i.e., CTR cell $3 \mathrm{~h}$ ) using the $\Delta \Delta \mathrm{Ct}$ method. Finally, the fold change expression of each gene was calculated as $2^{-\Delta \Delta C T}[24]$.

\section{AMSC surface expression of MHC I and MHC II by flow cytometry}

Aliquots of naïve and pre-conditioned AMSCs were analyzed at passage P3 with $100 \mu \mathrm{l}$ Mouse anti Equine MHC Class 1 primary antibody (Bio-Rad, CA, USA; clone CVS22) and Mouse anti Equine MHC Class II antibody (Bio-Rad; clone CVS20) in PBS 3\% BSA for $45 \mathrm{~min}$ at room temperature in the dark. After incubation, MSC analyzed with MHC I and MHC II were washed in cold PBS and incubated in 100- $\mu$ l secondary FITC-conjugated goat anti-Mouse IgG antibody (Bio-Rad) for $20 \mathrm{~min}$ on ice in the dark. Finally, labeled cells were washed twice in ice-cold PBS and analyzed using Epics Coulter flow cytometer (Beckman Coulter-IL, Fullerton, CA, USA). A minimum of 10,000 cells were acquired for each sample and analyzed in the FL1 channel. All analyses were based on control cells incubated with isotype-specific IgGs to establish the background signal. Off-line analysis of the flow cytometry files was performed using Weasel software v.2.5.

\section{Lymphocyte proliferation test}

Horse peripheral blood mononuclear cells (PBMC) were obtained from heparinized whole blood samples using density gradient centrifugation (Lymphoprep; AxisShield, Oslo, Norway) at $500 \mathrm{~g}$ without brakes for $20 \mathrm{~min}$ at room temperature. Informed consent was obtained from the owners for blood collection.

To study the effects of equine AMSCs on lymphocyte proliferation in a cell-to-cell contact setting, different numbers of AMSCs from each amniotic membrane were seeded per well $\left(0.1 \times 10^{5}, 0.5 \times 10^{5}, 1 \times 10^{5}\right)$ in RPMI complete medium supplemented with $10 \%$ heatinactivated FBS, $2 \mathrm{mML}$-glutamine, and penicillin 10 , $000 \mathrm{U} / \mathrm{ml}$, streptomycin $10 \mathrm{mg} / \mathrm{ml}(\mathrm{P} / \mathrm{S})$ and left to adhere overnight. The next day, AMSCs were gammairradiated (3000 cGy) to ensure that the proliferation observed could be attributed solely to the proliferation of responder lymphocytes. Then, $2 \times 10^{5}$ equine peripheral blood mononuclear cells (PBMCs) were added to each well in ultra-culture serum-free medium supplemented with $2 \mathrm{mM} \mathrm{L}$-glutamine (Sigma) and penicillin 10,000 U/ $\mathrm{ml}$, streptomycin $10 \mathrm{mg} / \mathrm{ml}(\mathrm{P} / \mathrm{S})$.

To study the paracrine effects of equine AMSCs on lymphocyte proliferation, $10 \mu \mathrm{L}, 50 \mu \mathrm{L}$, or $100 \mu \mathrm{L}$ of $\mathrm{CM}$ -

Table 1 Oligonucleotide sequences used for RT-PCR analysis

\begin{tabular}{|c|c|c|c|}
\hline Markers & Sequences $\left(5^{\prime} \rightarrow 3^{\prime}\right)$ & Product size (bp) & Annealing temperature $\left({ }^{\circ} \mathrm{C}\right)$ \\
\hline Glyceraldehyde-3-phosphate dehydrogenase (GAPDH) & $\begin{array}{l}\text { S: AGATCAAGAAGGTGGTGAAG } \\
\text { A: TTGTCATACCAGGAAATGAGC }\end{array}$ & 168 & 60 \\
\hline Major histocompatibility complex I (MHC-1) & $\begin{array}{l}\text { S: GGAGAGGAGCAGAGATACA } \\
\text { A: CTGTCACTGTITGCAGTCT }\end{array}$ & 218 & 55 \\
\hline Major histocompatibility complex II (MHC-II) & $\begin{array}{l}\text { S: TCTACACCTGCCAAGTG } \\
\text { A: CCACCATGCCCTITCTG }\end{array}$ & 178 & 55 \\
\hline
\end{tabular}


AMSC, CM-AMSC-TNF- $\alpha, \quad$ CM-AMSC-IFN- $\gamma$, and CM-AMSC-TNF- $\alpha+$ IFN- $\gamma$ of each amniotic membrane were added to $2 \times 10^{5}$ PBMCs in each well. A nonconditioned medium (non-CM) used as a control was generated in the same way as above, except that no cells were cultured in the plates. Another control was represented by PBMCs alone (unstimulated). For both studies with AMSCs and CM, PBMCs were stimulated with $2 \mu \mathrm{g} / \mathrm{mL}$ phytohemagglutinin (PHA).

All cultures were carried out in triplicate in flatbottomed 96-well tissue culture plates (Corning, Milan, Italy) in a final volume of $200 \mu \mathrm{l}$.

Lymphocyte proliferation was assessed after 3 days of culture by adding $0.67 \mu \mathrm{Ci}$ of $[3 \mathrm{H}]$-thymidine (Perkin Elmer) per well for 16-18 h. Cells were then harvested with a Filtermate Harvester (PerkinElmer), and $[3 \mathrm{H}]$-thymidine incorporation was measured using a microplate scintillation and luminescence counter (Top Count NXT; PerkinElmer).

\section{In vitro effect of $\mathrm{CM}$ on endometrial cell viability and apoptosis}

The dose-response curve of LPS on endometrial cells was studied showing that $10 \mathrm{ng} / \mathrm{ml}$ of LPS for $24 \mathrm{~h}$ was most effective in inducing cellular stress evaluated by apoptosis [25]. Sixty thousand cells were incubated with LPS $10 \mathrm{ng} /$ $\mathrm{ml}$ for $24 \mathrm{~h}$ and with $10 \%$ of CM-AMSC or CM derived from AMSCs primed (CM-AMSC-TNF- $\alpha$, CM-AMSCIFN- $\gamma$, CM-AMSC-TNF- $\alpha+$ IFN- $\gamma$ ).

Endometrial cells alone, endometrial cells with LPS, and endometrial cells with different $\mathrm{CM}$ were used as controls.

Cell viability and apoptosis of endometrial cells stressed by LPS and treated with $10 \%$ of different CM were assessed using a combination of acridine orange (AO) and propidium iodide (PI) staining. Briefly, reagent solutions were prepared by dissolving $3 \mathrm{mg}$ of PI in $1 \mathrm{ml}$ of absolute ethanol and $5 \mathrm{mg}$ of $\mathrm{AO}$ in $1 \mathrm{ml}$ of ethanol and stored at $4{ }^{\circ} \mathrm{C}$. A working solution was obtained by mixing $1 \mu \mathrm{l}$ of AO solution, $1 \mu \mathrm{l}$ of PI solution, and $1 \mathrm{ml}$ phosphate buffer solution (PBS).

At each time point, the cell monolayer was trypsinized and the cell suspension was centrifuged at $250 \mathrm{~g}$ for 10 min. Fifty microliters of pellets were diluted with $50 \mu \mathrm{l}$ of working solution. Examination under a fluorescence light microscope (Olympus BX51, Japan) at a magnification of $\times 40$ was performed immediately. Acridine orange dye was excited at $460 \mathrm{~nm}$ while the emission wavelength was set at $650 \mathrm{~nm}$. Propidium iodide was excited at $535 \mathrm{~nm}$ while the emission wavelength was set at 617 $\mathrm{nm}$. According to the literature [26], cell staining and morphology were considered to define viable cells, apoptotic cells, and necrotic cells. Under a fluorescence microscope, viable cells showed normal nuclei staining with green chromatin; apoptotic cells showed condensed or fragmented chromatin (green or orange) and budding of the cell membrane; necrotic cells had similar normal nuclei staining as viable cells except the chromatin was orange or red instead of green.

\section{In vitro effect of $\mathrm{CM}$ on endometrial cell mitochondrial activity and ROS levels}

For assessing the bioenergetic/oxidative status of endometrial cells stressed by LPS and treated with $10 \% \mathrm{CM}$, $1 \times 10^{4}$ cells were seeded in $35 \mathrm{~mm}$ Petri dishes onto coverslips and cultured in the conditions described previously, until $50 \%$ confluence was reached. To investigate mitochondrial distribution and apparent energy status, cells were washed three times in PBS with $3 \%$ bovine serum albumin (BSA) and incubated for $30 \mathrm{~min}$ in the same medium containing $280 \mathrm{nM}$ MitoTracker Orange CMTM Ros (Molecular Probes, OR, USA) at $38.5^{\circ} \mathrm{C}$ under $5 \% \mathrm{CO}_{2}[27,28]$. The probe contains a thiol-reactive chloromethyl moiety and passively enters the cell membrane. The probe is readily sequestered only by active mitochondria, and it can react with accessible thiol groups on peptides and proteins to form an aldehyde-fixable conjugate $[29,30]$.

After incubation with a mitochondrial probe, cells were washed three times in PBS with 0.3\% BSA and incubated for $15 \mathrm{~min}$ in the same media containing $10 \mu \mathrm{M} 2^{\prime}, 7^{\prime}$ dichlorodihydrofluorescein diacetate (H2DCF-DA) [3133] to detect intracellular ROS. This probe is membranepermeant and can diffuse into cells. Once inside the cell, the acetate groups are hydrolyzed by intracellular esterase producing $\quad 2^{\prime}, 7^{\prime}$-dichlorodihydrofluorescein (H2DCF) which is a polar molecule and thus retained inside the cell. $\mathrm{H} 2$ DCF fluoresces when it is oxidized by $\mathrm{H}_{2} \mathrm{O}_{2}$ or lipid peroxides to produce $2^{\prime}, 7^{\prime}$-dichlorofluorescein (DCF). The level of DCF is related linearly to that of peroxides, and thus, its fluorescence provides a measure of peroxide levels [30]. The cells were then fixed with $2 \%$ paraformaldehyde in PBS for $2 \mathrm{~h}$, stained with $2.5 \mathrm{mg} / \mathrm{mL}$ Hoechst 33258 in 3:1 of glycerol to PBS solution, and mounted onto slides in the same solution. Evaluation of fluorescence intensities and nuclear chromatin was performed using a Zeiss epifluorescence microscope at $\times 200$ magnification. For the quantification analysis, 5 randomly selected microscope fields were evaluated (around 300 cells for each experimental condition) by using ImageJ software (Rasband, W.S., ImageJ, US National Institutes of Health, Bethesda, MD, USA, https://imagej.nih.gov/ij/, 19972018.). Fluorescence intensities are expressed as arbitrary densitometric units (ADU).

\section{Statistical analysis}

Data are expressed as mean \pm standard deviation. Differences between AMSC or CM-AMSC and controls were analyzed by the analysis of variance (ANOVA) followed by Tukey's multiple comparisons test. 
For immunogenicity markers, statistical differences were determined using ANOVA followed by Dunnett's multiple comparison test, the Tukey-Kramer multiple comparisons test, or unpaired $t$ test.

Differences were considered statistically significant if $P$ was $<0.05$.

Statistical analysis was performed with GraphPad Prism 6 Software (GraphPad Software, San Diego, CA, USA).

\section{Results}

\section{Tissue collection and cell isolation}

Cell selection was based on the ability of cells to adhere to plastic. Trypan blue exclusion assay showed that the initial viability was $>90 \%$ for AMSCs and $>85 \%$ for endometrial cells. As expected, for all mesenchymal stromal cell phenotypes, the AMSCs at P3 express CD29, CD44, CD106, CD105, and lack CD34 (Fig. 1a). Moreover, AMSCs are able to differentiate in mesenchymal (osteogenic, adipogenic, and chondrogenic) and ectodermic lineages (neurogenic) as reported by LangeConsiglio et al. [21].

Molecular biology analyses of endometrial cells at P0 confirmed the expression of PR, MPR, PGRMC1, and HOXA-9 (Fig. 1b).

\section{Gene expression of immunogenicity markers}

The gene expression of $M H C I$ and $M H C I I$ after priming was assessed. In all tested conditions, the cells had a similar expression of MHC I with values similar to control cells and lacked the gene expression of MHC II (Fig. 2).

\section{AMSC surface expression of MHC I and MHC II}

Representative immunophenotype patterns of naïve and pre-conditioned AMSCs are reported in Fig. 3. All populations were negative for $\mathrm{MHCII}$ and positive for $\mathrm{MHCI}$ (average $56.25 \%$, range $40-70 \%$ ).

\section{Lymphocyte proliferation test}

In all the conditions tested (naïve AMSC (CTR) and AMSC primed with TNF- $\alpha$, or IFN- $\gamma$, or with a combination of TNF- $\alpha$ and IFN- $\gamma$ ), the proliferation of PBMC activated with PHA was inhibited in a dose-dependent manner (Fig. 4a) and stronger effects were observed at a PBMC: AMSC ratio of 1:0.5 and with $100 \mu \mathrm{L} /$ well of CM. No significant differences were observed between naive AMSC and AMSC stimulated with TNF- $\alpha$ or IFN- $\gamma$ (with $1 \times 10^{5}$ AMSC the inhibition of PBMC proliferation was of $91.33 \pm 5.03 \%$ for naïve AMSC, $85.00 \pm 9.85 \%$ for TNF$\alpha, 78.00 \pm 17.52 \%$ for IFN- $\gamma$ ). Conversely, a combination of TNF- $\alpha$ and IFN- $\gamma$ priming decreased capacity of AMSCs to inhibit proliferation when compared to naïve AMSCs $(63.00 \pm 26.96 \%$ inhibition; Fig. 4a). This difference was possibly due to the lower AMSC viability after double cytokine stimulation $(58 \% \pm 11.6 \%)$ when compared to the

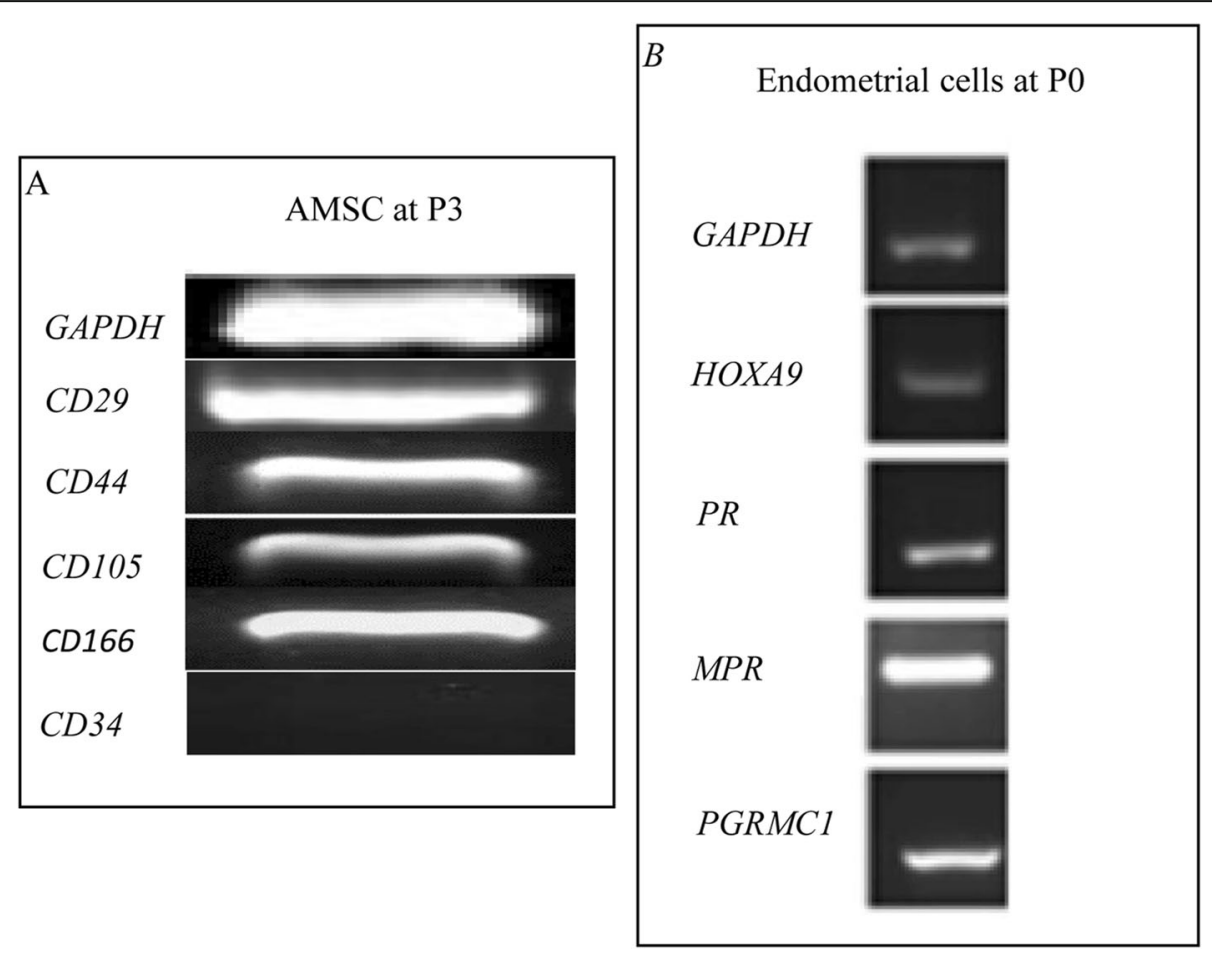

Fig. 1 Molecular biology analyses. a Mesenchymal stromal cell phenotype of AMSCs at P3. b Molecular expressions of endometrial cells at P0 


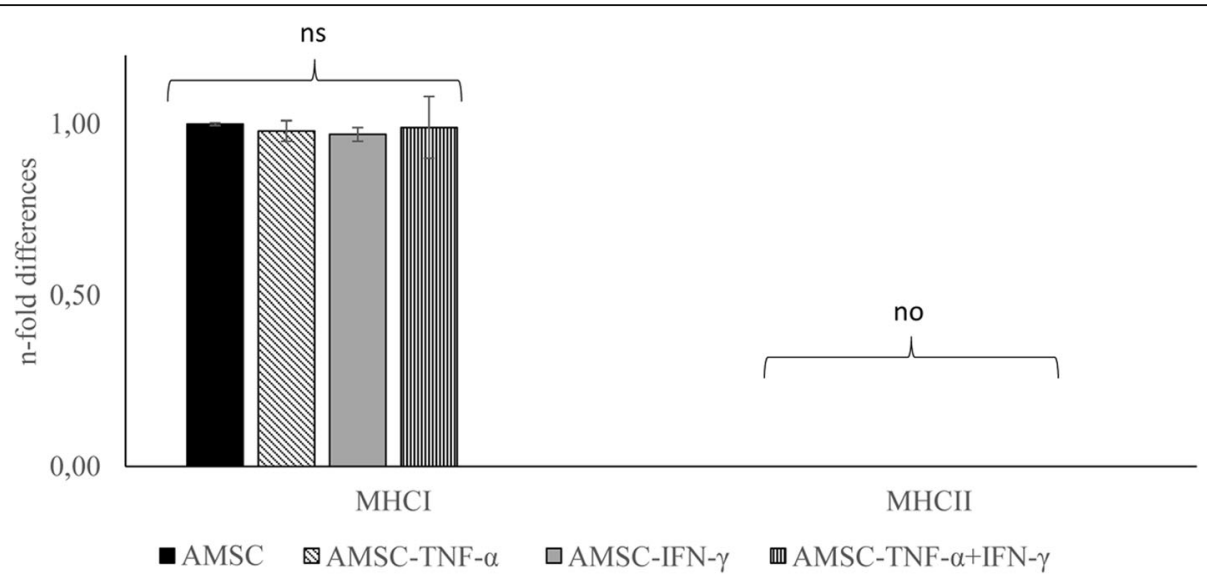

Fig. 2 Equine amniotic-derived mesenchymal cell (AMSC) gene expression studied by real-time quantitative polymerase chain reaction (qRT-PCR) under the four culture conditions: AMSC, AMSC conditioning by TNF-a (AMSC-TNF- $a$ ), IFN- $\gamma$ (AMSC-IFN- - ), or a combination of TNF- $a$ and IFN- $\gamma$ (AMSC-TNF-a+IFN- - ). Gene expression is shown as mean \pm SD $(n=3)$ fold change versus standard condition (AMSC). ns = not significant; no = not observed

single cytokine stimulation $(78 \% \pm 2.7 \%$ for $\mathrm{TNF}-\alpha$ and $77 \% \pm 2.4 \%$ for IFN $-\gamma)$ and to naïve AMSCs $(72 \% \pm 4.8 \%)$.

In addition, we showed that CM-AMSC can also inhibit the proliferation of PBMC in a dose-dependent manner (Fig. 4b). No differences were observed in the inhibitory ability between the different cytokine stimulation conditions: with $100 \mu \mathrm{L} /$ well, $96.00 \pm 1.00 \%$ inhibition with CM-AMSC, $97.00 \pm 1.00 \%$ for CM-AMSCTNF- $\alpha, \quad 94.33 \pm 2.89 \%$ for CM-AMSC-IFN- $\gamma$, and $95.67 \pm 2.52$ with the combination CM-AMSC-TNF$\alpha+$ IFN- $\gamma$.

The same data are shown in Fig. 3 as count/minute.

\section{In vitro effect of $\mathrm{CM}$ on endometrial cell viability and apoptosis}

Data for viability and apoptotic staining are reported in Table 2. These results demonstrate that LPS treatment induces $38.68 \%$ endometrial cell death and $39.66 \%$ apoptosis, with only $21.66 \%$ of live cells present at $24 \mathrm{~h}$. In the presence of $10 \%$ CM-AMSC, the effect of LPS was countered, indeed, $65.59 \pm 3.12 \%$ of endometrial cells were viable at $24 \mathrm{~h}$ of culture. In the presence of LPS and CM derived from priming with TNF- $\alpha$, IFN- $\gamma$, and the combination of the 2 cytokines, endometrial cell viability was $64.31 \pm 1.48 \%, 64.87 \pm 5.24 \%$, and $64.12 \pm$ $0.95 \%$, respectively, and there were no statistical significant differences compared to CM-AMSC.

\section{In vitro effect of $\mathrm{CM}$ on endometrial cell mitochondrial activity and ROS levels}

To establish the mechanisms underlying the damaging effects of LPS on endometrial cells, the energy/oxidative conditions of the cells exposed to different stimuli were investigated. We found that exposure of endometrial cells to LPS induced a substantial modification of the bioenergetic/oxidative status of this cell line. In fact, it increased both the mitochondrial activity (Fig. 5, panel a) and intracellular ROS levels (Fig. 5, panel b), compared with the basal, naïve AMSCs (CTR), and condition $(P<0.05)$. Moreover, it was interesting to find that LPSstressed endometrial cells treated with $\mathrm{CM}$ derived from cells primed with TNF- $\alpha$ or IFN- $\gamma$ or their combination restored their bioenergetic/oxidative status (by reducing mitochondrial activity and ROS levels) to values similar to those identified in the naïve AMSCs (CTR) and CMAMSC $(P<0.05)$. Figures 6 and 7 show representative images of endometrial cells analyzed under an epifluorescence microscope. Increased fluorescence intensities of mitochondria- and ROS-specific probes are visible in the LPS-exposed sample compared with CTR, CM-AMSC, and LPS+CM conditions.

\section{Discussion}

In MSC-based therapy, the priority is to develop in vitro culture methods that mimic the natural MSC niche, allowing cell expansion for clinical use, while maintaining cell quality and function. In recent years, priming approaches to increase the therapeutic potential of MSCs have been investigated. Priming (also referred to as licensing or preconditioning) with pro-inflammatory mediators consists of preparing cells for some specific function or lineage-specific differentiation, which involves cell activation, molecular signaling, genetic, or epigenetic modifications [16]. This strategy is effective in promoting immunoregulatory properties when compared to unprimed cells; indeed, adipose tissue-derived MSCs are not able to inhibit proliferation of PBMCs without exposure to IFN- $\gamma$ indicating that inhibitory factors are released on MSC activation [34]. In addition, others have shown a significantly enhanced immune- 


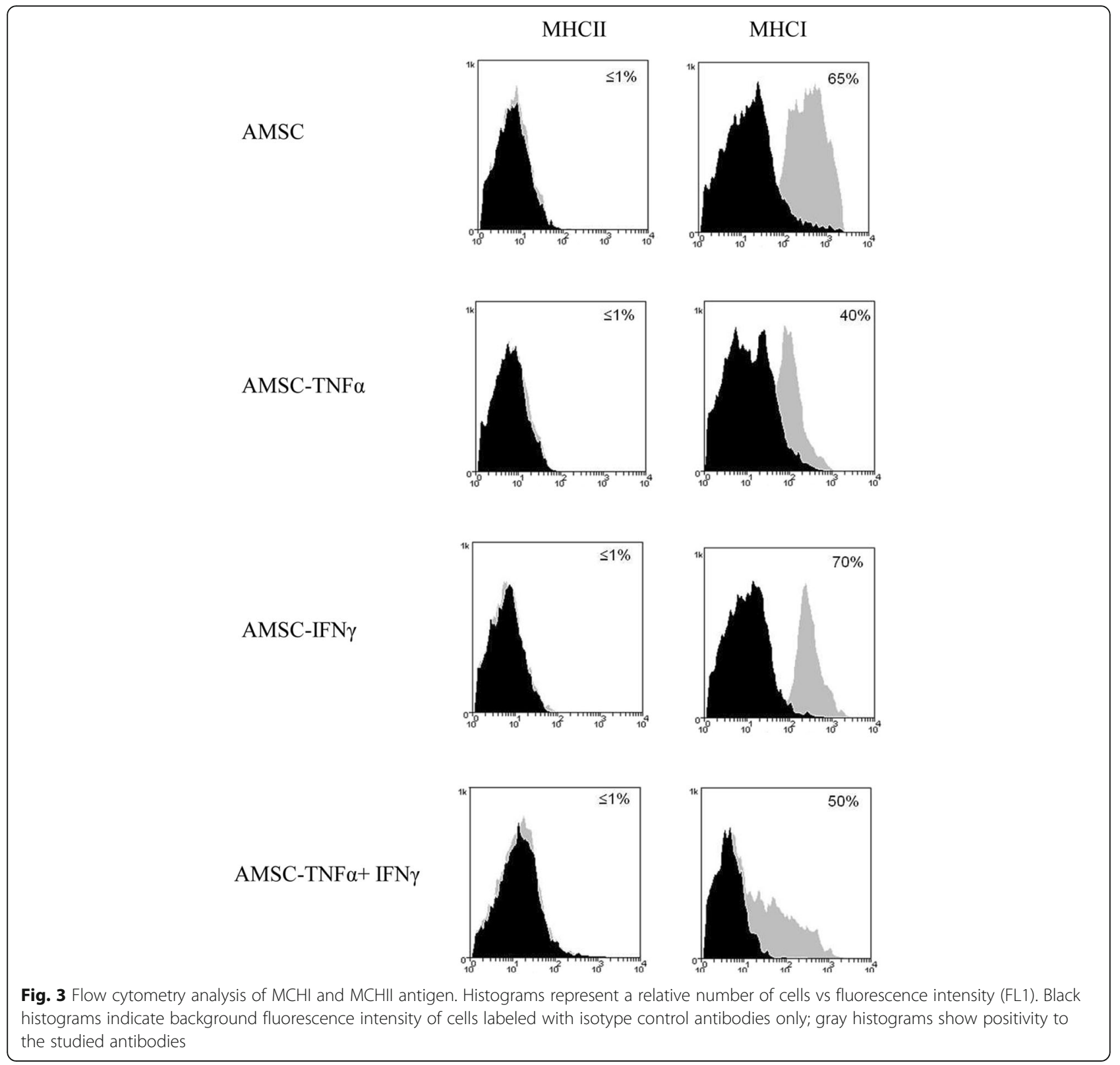

suppressive potential for the umbilical cord- and bone marrow-derived MSCs after IFN- $\gamma$ stimulation [35]. Specifically, several studies indicate that the human bone marrow-derived cells (BM-MSCs [18, 36-39] and equine BM-MSCs $[15,40])$ need to be "licensed" by inflammatory signaling to become fully immunosuppressive.

Conversely, we have previously demonstrated that naïve equine AMSCs can inhibit the proliferation of equine PBMCs when cultured in both cell-to-cell contacts and when separated by a transwell membrane, suggesting that intrinsically secreted factors are involved in the process. Accordingly, we also demonstrated that the proliferation of PBMCs was also inhibited by the CM generated from naïve AMSC [19].
In the present paper, AMSC priming did not enhance their ability to inhibit lymphocyte proliferation compared to controls. The only statistically significant difference was with AMSCs primed with both TNF- $\alpha$ and IFN- $\gamma$. Our previous study reported that CM from horse AMSCs significantly reduced the production of TNF- $\alpha$, together with a trend to reduction of TGF- $\beta$ and IL- 6 release from alveolar macrophages stimulated with LPS [41], and it remains to be investigated whether or not priming could enhance these effects.

Double primed AMSCs were able to inhibit PBMC proliferation, even if the AMSC viability was lower than the other experimental conditions (58\%). It is known that inflammatory exposure can diminish MSC viability 


\section{$\mathrm{PBMC}+\mathrm{PHA}$}

$+\operatorname{AMSC}\left(0.1 \times 10^{5}\right.$ cells $)$ or CM-AMSC $(10 \mu \mathrm{L})$

$+\operatorname{AMSC}\left(0.5 \times 10^{5}\right.$ cells) or CM-AMSC $(50 \mu \mathrm{L})$

A.

$+\operatorname{AMSC}\left(1 \times 10^{5}\right.$ cells) or CM-AMSC $(100 \mu \mathrm{L})$

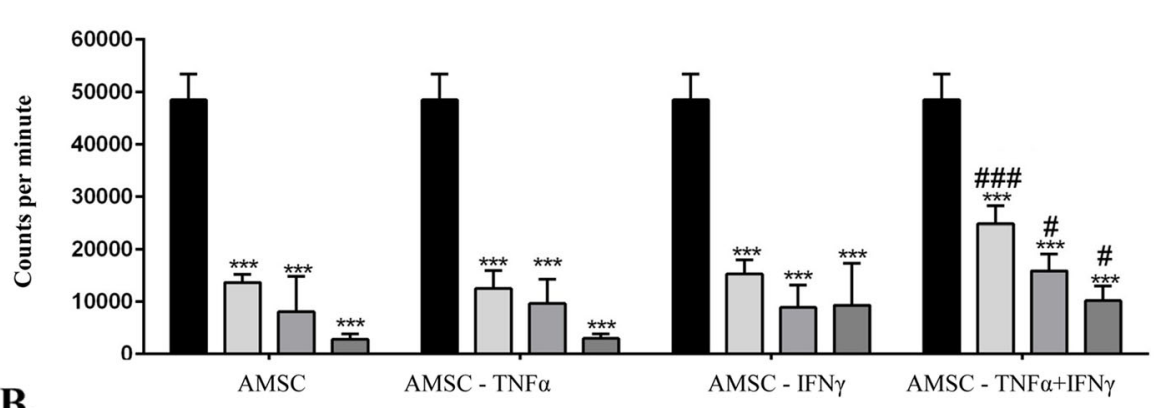

B.

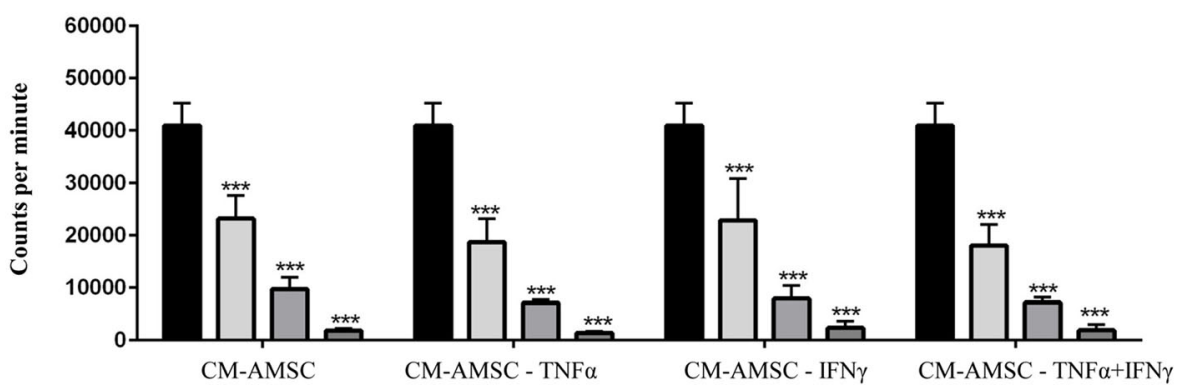

Fig. 4 Effects of equine AMSC (a) and AMSC-derived conditioned medium (CM) (b) on the proliferation of PHA-stimulated equine lymphocytes. a Different experimental conditions represented are naïve AMSC, AMSC-TNF-a, AMSC-IFN- $\gamma$, and AMSC-TNF- $\mathrm{a}+\mathrm{IFN}-\gamma .1 \times 10^{5}, 0.5 \times 10^{5}$, and $0.1 \times 10^{5}$ AMSC/well were cultured in contact with $2 \times 10^{5}$ PBMC stimulated with PHA. b Different experimental conditions represented are conditioned medium (CM) from naïve AMSC (CM-AMSC), CM from AMSC primed with TNF- $a$, with IFN- $\gamma$, or with both TNF- $a+I F N-\gamma$. Ten microliters, $50 \mu \mathrm{L}$, or $100 \mu \mathrm{L} C M-A M S C /$ well was added to $2 \times 10^{5}$ PBMC stimulated with PHA. Data representing the mean and standard deviation of three different AMSC preparations each of which was tested with two different lymphocyte donors, with the exception of the third AMSC which was tested with one lymphocyte donor. ${ }^{\#} p<0.05$; ${ }^{* *}$ and ${ }^{\# \# \#} p<0.001 .{ }^{*}$ vs PBMC+PHA, \# vs AMSC or CM-AMSC group

Table 2 Rate of live, dead, and apoptotic cells in different experimental conditions

\begin{tabular}{|c|c|c|c|}
\hline Condition & Live & Apoptotic & Dead \\
\hline$\overline{\mathrm{CTR}}$ & $88.00 \pm 2.12^{\mathrm{a}}$ & $9.83 \pm 1.23^{\mathrm{a}}$ & $2.17 \pm 1.02^{\mathrm{a}}$ \\
\hline CM-AMSC & $88.84 \pm 1.28^{\mathrm{a}}$ & $8.47 \pm 1.94^{a}$ & $2.69 \pm 0.82^{a}$ \\
\hline CM-AMSC-TNF- $a$ & $77.83 \pm 0.77^{b}$ & $16.22 \pm 0.74^{\mathrm{b}}$ & $5.95 \pm 0.03^{b}$ \\
\hline CM-AMSC-IFN- $\gamma$ & $77.09 \pm 0.37^{b}$ & $15.84 \pm 0.24^{b}$ & $7.07 \pm 0.12^{b}$ \\
\hline CM-AMSC-TNF- $a+I F N-\gamma$ & $59.38 \pm 0.59^{c}$ & $24.94 \pm 1.86^{c}$ & $15.68 \pm 1.27^{c}$ \\
\hline LPS & $21.66 \pm 6.88^{d}$ & $39.66 \pm 9.81^{d}$ & $38.68 \pm 6.69^{d}$ \\
\hline LPS+CM-AMSC & $65.59 \pm 2.55^{\mathrm{e}}$ & $23.97 \pm 2.59^{e}$ & $10.44 \pm 2.20^{\mathrm{e}}$ \\
\hline LPS+CM-AMSC-TNF-a & $64.31 \pm 1.48^{e}$ & $24.96 \pm 2.73^{e}$ & $10.73 \pm 1.30^{\mathrm{e}}$ \\
\hline LPS+CM-AMSC-IFN- $\gamma$ & $64.87 \pm 5.24^{\mathrm{e}}$ & $24.00 \pm 4.01^{\mathrm{e}}$ & $11.13 \pm 2.15^{\mathrm{e}}$ \\
\hline LPS + CM-AMSC-TNF- $a+I F N-\gamma$ & $64.12 \pm 0.95^{\mathrm{e}}$ & $22.46 \pm 3.46^{e}$ & $13.42 \pm 3.64^{\mathrm{e}}$ \\
\hline
\end{tabular}

Different small letters superscript $(a, b)$ in the different columns indicate statistically different comparisons $(P<0.05)$
[42], even though the effect of priming on AMSC survival in vivo remains to be determined.

It is possible that there are other mechanisms by which MSCs participate in regeneration [43]; indeed, CM obtained from both naive and primed AMSCs was able to strongly inhibit PBMC proliferation, suggesting that the key mediators for the inhibition of proliferation are constitutively expressed not only in the AMSCs but also in their secretome. These data confirm our previous observations demonstrating that $\mathrm{CM}$ from human AMSCs inhibits the proliferation of PBMCs without priming [2].

Herein, we also studied whether priming makes the AMSCs more responsive, by evaluating the effect of priming on cell viability and oxidative stress using a model of LPS-induced injury in endometrial cells. In endometrial cells, LPS induces damage at different levels, leading to mitochondrial dysfunction and ROS overproduction. We have shown that $\mathrm{CM}$ from naïve and primed AMSCs has a similar ability to increase the viability of LPS-stressed endometrial cells, thus suggesting 


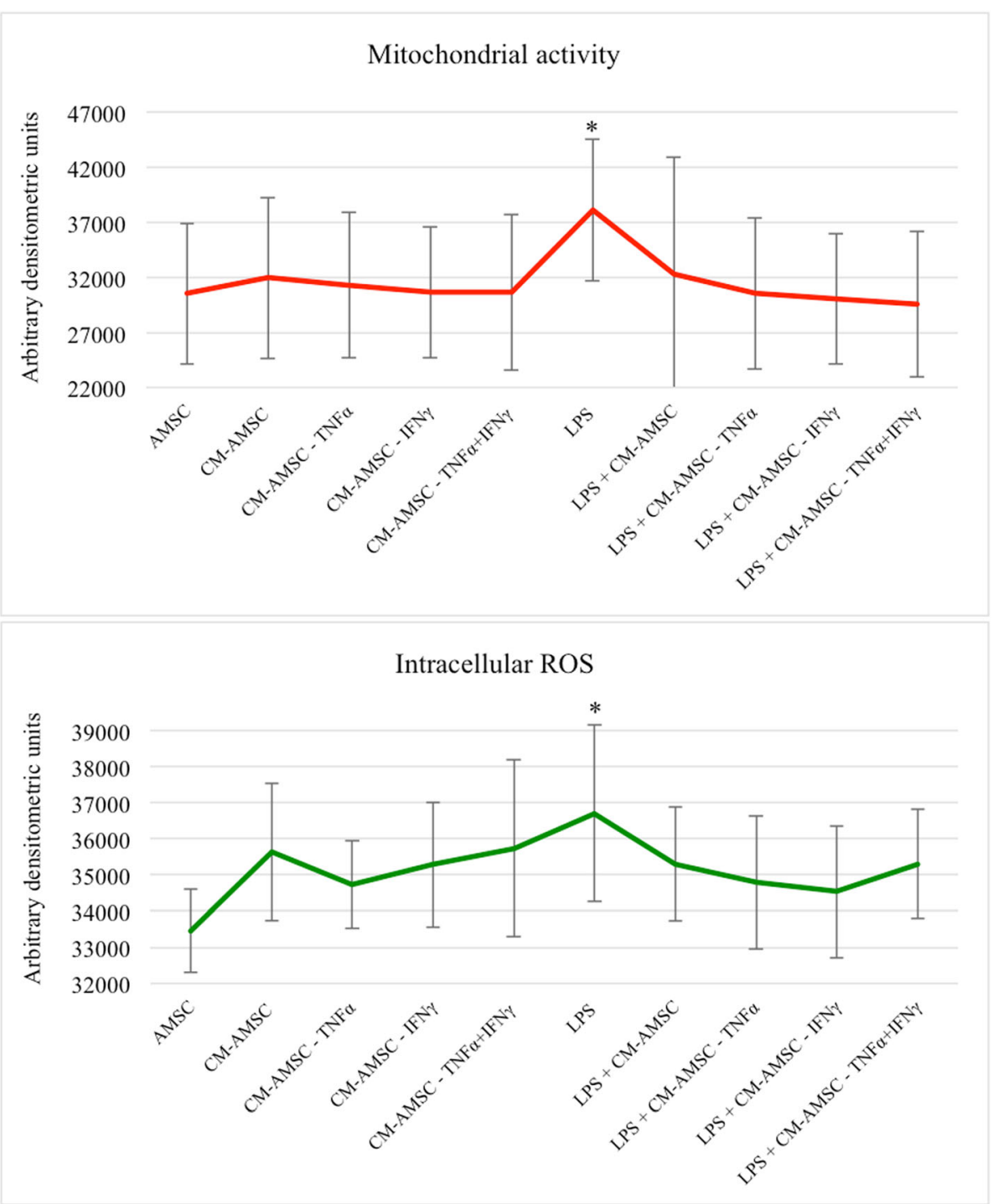

Fig. 5 Mitochondrial activity and ROS levels are expressed as means \pm SD of three different biological replicates with MitoTracker Orange (a) and dichlorodihydrofluorescein diacetate (DCDHFDA; b fluorescence intensity in arbitrary densitometric units (ADU). LPS-treated cells showed significantly increased mitochondrial and ROS levels compared with controls. The addition of CM alone or in combination with TNF and/or IFN restored the basal bioenergy status of endometrial cells. One-way ANOVA followed by Tukey post hoc test: * for $P<0.05$

that activation with pro-inflammatory cytokines is not a prerequisite to make the secretome more responsive to inflammatory environments. After LPS stimulation, only $21.66 \pm 8.43 \%$ of endometrial cells survived while approximately $65 \%$ of cells survived after treatment with CM obtained with different activations.

These data were confirmed by evaluating the bioenergetic/redox status of the endometrial cells. Oxidative stress is one of the main pathophysiological mechanisms for some inflammatory conditions [44]. LPS can induce increased oxidative stress and mitochondrial dysfunction, characterized by a decrease in mitochondrial protein expression, mitochondrial mass, and reduction in the mitochondrial membrane potential [44]. Our data demonstrates that CM derived from amniotic cells has beneficial effects on the bioenergetic/oxidative status of LPS-stressed endometrial cells. In fact, while LPS led to excessively driven mitochondria activity with consequent ROS generation, CM restored the basal bioenergy status identified in the CTR condition and there was no statistical difference between CM from naïve and primed cells. This suggests the paracrine mechanism of AMSCs, as we previously demonstrated by $\mathrm{CM}$ administration in spontaneous tendon lesions in sport horses [19], and by culturing endometrial cells in vitro in the presence of $\mathrm{CM}$, where a significant increase in proliferation rate 


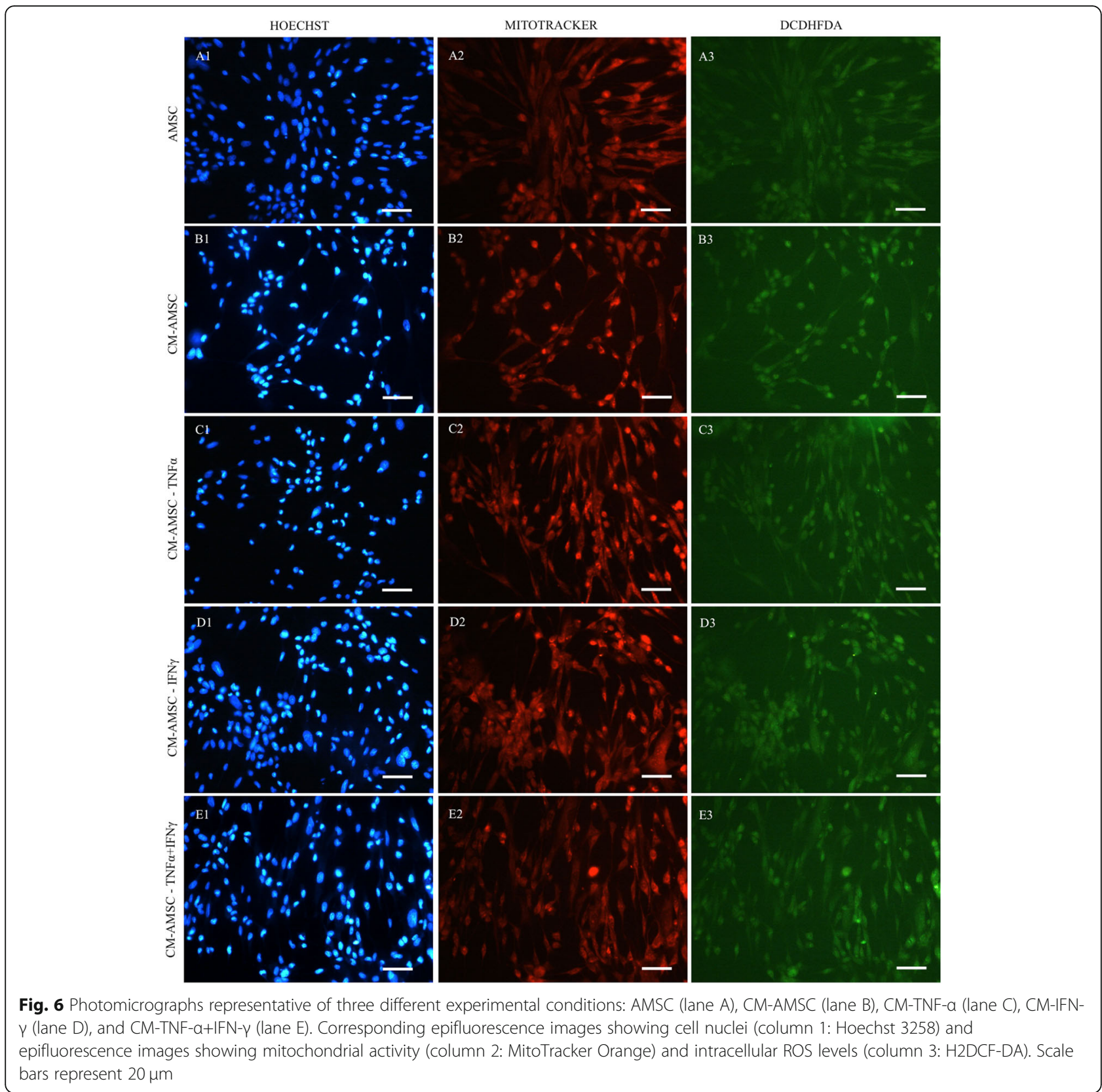

occurred. Thus, there is the potential to use the CM in vivo to improve endometrial cell replenishment [44].

To date, many pro-inflammatory cytokines or growth factors are used for priming MSCs isolated from different species and/or tissues. Also, for MSCs from different equine tissues, pro-inflammatory priming increases immunosuppressive properties by stimulating the secretion of anti-inflammatory and immunomodulatory factors [45]. The fact that we demonstrate that AMSCs do not require priming could underline the different immunomodulatory profile of MSCs from different tissues. Interestingly, our observation that cells from the amniotic membrane possess intrinsic immunological properties could be explained by the role of the placenta in the feto-maternal tolerance process during the development and growth of a semi-allogeneic fetus during pregnancy. Indeed, a successful pregnancy is characterized by distinct immunological stages: the first is a pro-inflammatory phase required for implantation and placentation, this is followed by an anti-inflammatory phase allowing for fetal growth and development, and the final stage is a pro-inflammatory process that is required for parturition [46]. Therefore, it could be hypothesized that AMSCs are already intrinsically/ 


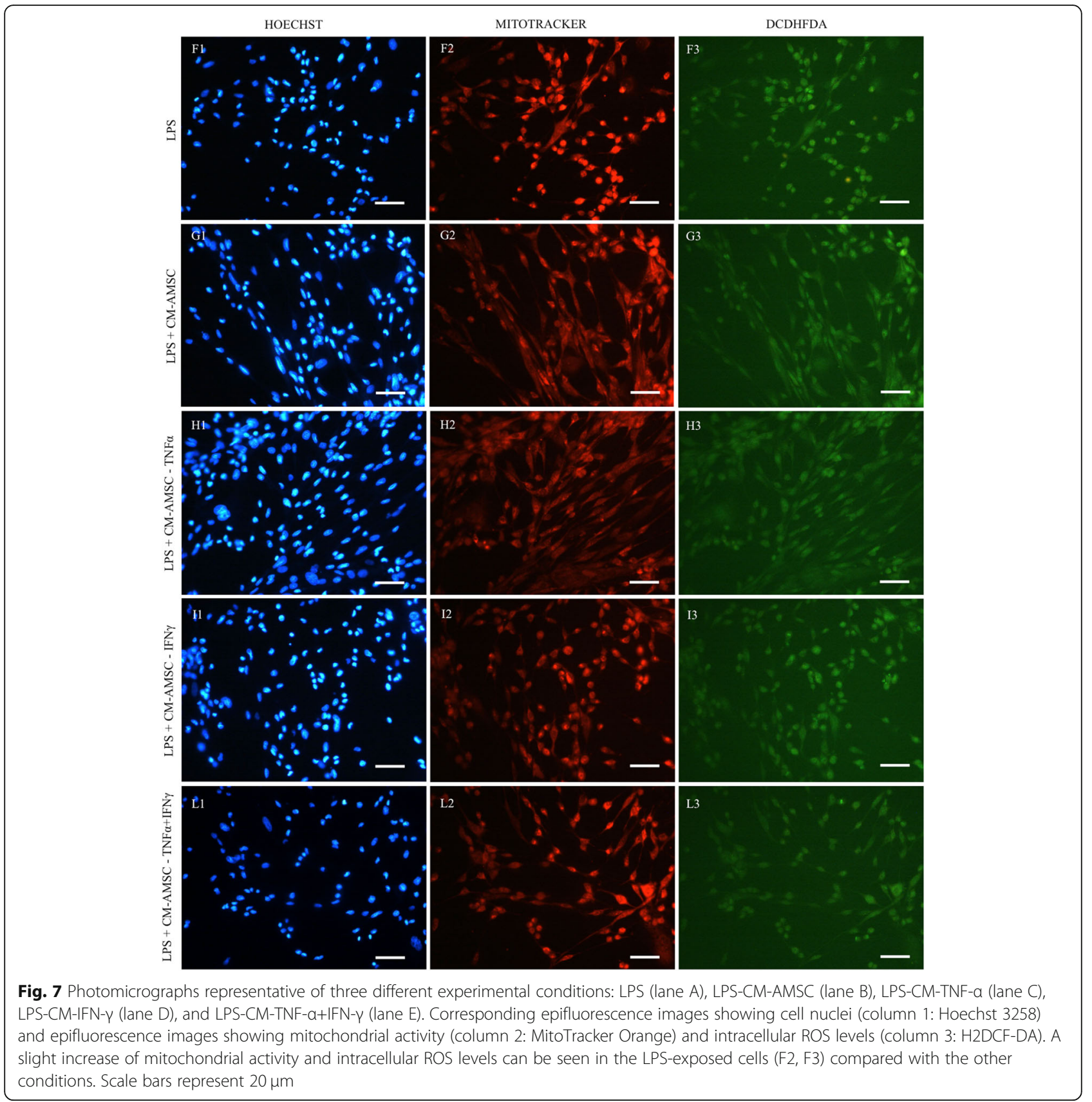

naturally primed by the inflammatory placental microenvironment from which they derive.

This suggests that AMSCs may be immediately prone to downregulate the lymphocyte response to promote healing when placed in an inflammatory niche dominated by TNF- $\alpha$ and IFN- $\gamma$.

This could explain the difference in priming results between bone marrow-derived cells and AMSCs in equine species. The priming protocol used in our study was the same as that used by Hill et al. [18] to license equine bone marrow-derived cells. After a 96- $\mathrm{h}$ priming with IFN- $\gamma$, in bone marrow-derived cells, there was an increase in cell surface expression of MHCI and MHC II while TNF- $\alpha$ priming increased MHCI expression only. With the same concentration of cytokines, the AMSC phenotype was unchanged and is thus independent of the environment.

\section{Conclusions}

In conclusion, the use of AMSCs may avoid the significant disadvantages associated with cell priming, such as the potential increase of immunogenicity [12, 15, 18], 
and the costs associated with cell culture and the use of expensive recombinant cytokines. The expression of MHCI and MHCII was similar to CTR after priming, confirming our previous cell characterization [21]. The use of AMSCs represents an alternative and promising source of MSCs and offers the potential for the production of cost-effective off-the-shelf cells and cell-free products from biological waste without priming.

\section{Abbreviations}

ADU: Arbitrary densitometric units; AMSCs : Amniotic mesenchymal stromal cells; ANOVA: Analysis of variance; AO: Acridine orange; BM-MSCs: Bone marrow mesenchymal stromal cells; BSA: Bovine serum albumin; CCCP: Carbonyl cyanide 3-chlorophenyl hydrazone; CCL2: C-C motif chemokine ligand 2; CDNA: Complementary DNA; CM: Conditioned medium; CM-AMSC: CM derived from naïve AMSCs; CT: Threshold cycle; DCF: 2',7'Dichlorofluorescein; DMSO: Dimethyl sulfoxide;

EDTA: Ethylenediaminetetraacetic acid; FBS: Fetal bovine serum; GAPDH: Glyceraldehyde 3-phosphate dehydrogenase; H2DCF: 2',7'Dichlorodihydrofluorescein; H2DCF-DA: 2',7'-Dichlorodihydrofluorescein diacetate; HG-DMEM: High-glucose Dulbecco's modified Eagle's medium; HGF: Hepatocyte growth factor; HOXA-9: Homeobox protein hox-a9-like;

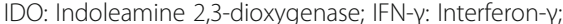

LPS: Lipopolysaccharide; MHC: Major histocompatibility complex; MPR: Membrane-associated progesterone receptor; MSC1: Mesenchymal stromal cells with pro-inflammatory phenotype; MSC2: Mesenchymal stromal cells with immunosuppressive phenotype; MSCs: Mesenchymal stromal cells; P/S: Penicillin/streptomycin; PBMCs: Peripheral blood mononuclear cells; PBS: Phosphate buffer solution; PGE2: Prostaglandin-E2; PGRMC1: Membranebound intracellular progesterone receptor component 1;

PHA: Phytohemagglutinin; PI: Propidium iodide; PR: Progesterone receptor; qPCR: Real-time quantitative polymerase chain reaction; RNA: Ribonucleic acid; ROS: Reactive oxygen species; RT-PCR: Reverse transcription-polymerase chain reaction; TGF- $\beta 1$ : Transforming growth factor $\beta 1$; TLR: Toll-like receptor; TNF-a: Tumor necrosis factor-a

\section{Acknowledgements}

We thank the Università degli Studi di Milano and the horse's owners for their availability in this study.

\section{Authors' contributions}

ALC contributed to the concept and design; isolation of amniotic cells; production of CM, amniotic, and endometrial cell culture; coordination of all experiments; collection and assembly of all data; analysis and interpretation of data; manuscript writing; and final approval of the manuscript. PR and MM contributed to the in vitro experiment of PBMC proliferation, interpretation of data, and final approval of the manuscript. AS contributed to the in vitro experiment of PBMC proliferation, interpretation of data, manuscript writing, and final approval of the manuscript. Al contributed to the cell cultures, cell staining, PCR analyses, collection and assembly of data of vitality, and final approval of the manuscript. NM contributed to the mitochondrial activity and ROS level analyses, interpretation of data, and final approval of the manuscript. FC contributed to the concept and design, interpretation of data, financial support, and final approval of the manuscript. OP contributed to the concept and design, analysis and interpretation of data, financial support, and final approval of the manuscript.

\section{Funding}

Supported by Università degli Studi di Milano.

\section{Availability of data and materials}

All data generated and/or analyzed during this study are included in this article.

\section{Ethics approval and consent to participate}

All procedures to collect the allanto-amniotic membrane were conducted following the standard veterinary practice and in accordance with the 2010/ 63 EU directive on animal protection and Italian Law (D.L. No. 116/1992). Equine blood collection was approved by the University of Milan Ethics
Committee (Protocol Number 41/15), and informed owner consent was obtained.

\section{Consent for publication}

Not applicable.

\section{Competing interests}

The authors declare that they have no competing interests.

\section{Author details}

${ }^{1}$ Department of Veterinary Medicine (DIMEVET), Università degli Studi di Milano, Via dell'Università 6, 26900 Lodi, Italy. ${ }^{2}$ Centro Ricerca E. Menni, Fondazione Poliambulanza di Brescia, Via Bissolati 57, 25124 Brescia, Italy. ${ }^{3}$ Department of Veterinary Science, University of Torino, Via Leonardo da Vinci 44, 10095 Turin, Italy. ${ }^{4}$ Department of Life Scince and Public Health, Università Cattolica del Sacro Cuore di Roma, Largo F. Vito 1, 00168 Rome, Italy.

Received: 23 October 2019 Revised: 8 February 2020

Accepted: 18 February 2020 Published online: 04 March 2020

\section{References}

1. Chen PM, Yen ML, Liu KJ, Sytwu HK, Yen BL. Immunomodulatory properties of human adult and fetal multipotent mesenchymal stem cells. J Biomed Sci. 2011:18:49.

2. Rossi D, Pianta S, Magatti M, Sedlmayr P, Parolini O. Characterization of the conditioned medium from amniotic membrane cells: prostaglandins as key effectors of its immunomodulatory activity. PLoS One. 2012;7(10):e46956.

3. Lohan P, Treacy O, Griffin MD, Ritter T, Ryan AE. Anti-donor immune responses elicited by allogeneic mesenchymal stem cells and their extracellular vesicles: are we still learning? Front Immunol. 2017;8:1626.

4. Krampera M. Mesenchymal stromal cell 'licensing': a multistep process. Leukemia. 2011;25(9):1408-14.

5. Bartholomew A, Sturgeon C, Siatskas M, Ferrer K, Mclntosh K, Patil S, et al Mesenchymal stem cells suppress lymphocyte proliferation in vitro and prolong skin graft survival in vivo. Exp Hematol. 2002;30(1):42-8.

6. Petrie Aronin CE, Tuan RS. Therapeutic potential of the immunomodulatory activities of adult mesenchymal stem cells. Birth Defects Res C Embryo Today. 2010;90(1):67-74

7. Waterman RS, Tomchuck SL, Henkle SL, Betancourt AM. A new mesenchymal stem cell (MSC) paradigm: polarization into a proinflammatory MSC1 or an immunosuppressive MSC2 phenotype. PLoS One. 2010;5(4):e10088.

8. Rivera-Cruz CM, Shearer JJ, Figueiredo Neto M, Figueiredo ML. The immunomodulatory effects of mesenchymal stem cell polarization within the tumor microenvironment niche. Stem Cells Int. 2017;2017:4015039.

9. Zimmermann JA, Hettiaratchi MH, McDevitt TC. Enhanced immunosuppression of T cells by sustained presentation of bioactive interferon-gamma within three-dimensional mesenchymal stem cell constructs. Stem Cells Transl Med. 2017;6(1):223-37.

10. Wang M, Yuan Q, Xie L. Mesenchymal stem cell-based immunomodulation: properties and clinical application. Stem Cells Int. 2018;2018:3057624.

11. Cunningham CJ, Redondo-Castro E, Allan SM. The therapeutic potential of the mesenchymal stem cell secretome in ischaemic stroke. J Cereb Blood Flow Metab. 2018;38(8):1276-92.

12. Leung VY, Chan D, Cheung KM. Regeneration of intervertebral disc by mesenchymal stem cells: potentials, limitations, and future direction. Eur Spine J. 2006;15(Suppl 3):S406-13.

13. Chan WK, Lau AS, Li JC, Law HK, Lau YL, Chan GC. MHC expression kinetics and immunogenicity of mesenchymal stromal cells after short-term IFNgamma challenge. Exp Hematol. 2008;36(11):1545-55.

14. English K. Mechanisms of mesenchymal stromal cell immunomodulation. Immunol Cell Biol. 2013:91(1):19-26.

15. Cassano JM, Schnabel LV, Goodale MB, Fortier LA. The immunomodulatory function of equine MSCs is enhanced by priming through an inflammatory microenvironment or TLR3 ligand. Vet Immunol Immunopathol. 2018;195: 33-9.

16. Noronha NC, Mizukami A, Caliari-Oliveira C, Cominal JG, Rocha JLM, Covas DT, et al. Priming approaches to improve the efficacy of mesenchymal stromal cell-based therapies. Stem Cell Res Ther. 2019;10(1):131. 
17. Najar M, Bouhtit F, Melki R, Afif H, Hamal A, Fahmi H, et al. Mesenchymal stromal cell-based therapy: new perspectives and challenges. J Clin Med. 2019;8(5):626-33

18. Hill JA, Cassano JM, Goodale MB, Fortier LA. Antigenicity of mesenchymal stem cells in an inflamed joint environment. Am J Vet Res. 2017;78(7):867-75.

19. Lange-Consiglio A, Rossi D, Tassan S, Perego R, Cremonesi F, Parolini O. Conditioned medium from horse amniotic membrane-derived multipotent progenitor cells: immunomodulatory activity in vitro and first clinical application in tendon and ligament injuries in vivo. Stem Cells Dev. 2013; 22(22):3015-24.

20. Ren G, Zhang L, Zhao X, Xu G, Zhang Y, Roberts Al, et al. Mesenchymal stem cell-mediated immunosuppression occurs via concerted action of chemokines and nitric oxide. Cell Stem Cell. 2008;2(2):141-50.

21. Lange-Consiglio A, Corradetti B, Bizzaro D, Magatti M, Ressel L, Tassan S, et al. Characterization and potential applications of progenitor-like cells isolated from horse amniotic membrane. J Tissue Eng Regen Med. 2012;6(8): 622-35

22. Donofrio G, Franceschi V, Capocefalo A, Cavirani S, Sheldon IM. Bovine endometrial stromal cells display osteogenic properties. Reprod Biol Endocrinol. 2008;6:65.

23. Corradetti B, Correani A, Romaldini A, Marini MG, Bizzaro D, Perrini C, et al. Amniotic membrane-derived mesenchymal cells and their conditioned media: potential candidates for uterine regenerative therapy in the horse. PLoS One. 2014;9(10):e111324.

24. Livak KJ, Schmittgen TD. Analysis of relative gene expression data using real-time quantitative PCR and the 2(-Delta Delta C(T)) method. Methods. 2001;25(4):402-8.

25. Perrini C, Strillacci MG, Bagnato A, Esposti P, Marini MG, Corradetti B, et al. Microvesicles secreted from equine amniotic-derived cells and their potential role in reducing inflammation in endometrial cells in an in-vitro model. Stem Cell Res Ther. 2016;7(1):169.

26. Ribble D, Goldstein NB, Norris DA, Shellman YG. A simple technique for quantifying apoptosis in 96-well plates. BMC Biotechnol. 2005;5:12.

27. Martino NA, Lacalandra GM, Filioli Uranio M, Ambruosi B, Caira M, Silvestre $F$, et al. Oocyte mitochondrial bioenergy potential and oxidative stress: within-/between-subject, in vivo versus in vitro maturation, and age-related variations in a sheep model. Fertil Steril. 2012;97(3):720-8.e1.

28. Somoskoi B, Martino NA, Cardone RA, Lacalandra GM, Dell'Aquila ME, Cseh S. Different chromatin and energy/redox responses of mouse morulae and blastocysts to slow freezing and vitrification. Reprod Biol Endocrinol. 2015; 13:22.

29. Poot M, Zhang YZ, Kramer JA, Wells KS, Jones LJ, Hanzel DK, et al. Analysis of mitochondrial morphology and function with novel fixable fluorescent stains. J Histochem Cytochem. 1996;44(12):1363-72.

30. Torner H, Brussow KP, Alm H, Ratky J, Pohland R, Tuchscherer A, et al. Mitochondrial aggregation patterns and activity in porcine oocytes and apoptosis in surrounding cumulus cells depends on the stage of preovulatory maturation. Theriogenology. 2004;61(9):1675-89.

31. Yang HW, Hwang KJ, Kwon HC, Kim HS, Choi KW, Oh KS. Detection of reactive oxygen species (ROS) and apoptosis in human fragmented embryos. Hum Reprod. 1998;13(4):998-1002.

32. Kuznetsov AV, Kehrer I, Kozlov AV, Haller M, Redl H, Hermann M, et al. Mitochondrial ROS production under cellular stress: comparison of different detection methods. Anal Bioanal Chem. 2011;400(8):2383-90.

33. Ambruosi B, Uranio MF, Sardanelli AM, Pocar P, Martino NA, Paternoster MS, et al. In vitro acute exposure to DEHP affects oocyte meiotic maturation, energy and oxidative stress parameters in a large animal model. PLoS One. 2011;6(11):e27452.

34. DelaRosa O, Lombardo E, Beraza A, Mancheno-Corvo P, Ramirez C, Menta R, et al. Requirement of IFN-gamma-mediated indoleamine 2,3-dioxygenase expression in the modulation of lymphocyte proliferation by human adipose-derived stem cells. Tissue Eng Part A. 2009;15(10):2795-806.

35. Deuse T, Stubbendorff M, Tang-Quan K, Phillips N, Kay MA, Eiermann T, et al. Immunogenicity and immunomodulatory properties of umbilical cord lining mesenchymal stem cells. Cell Transplant. 2011;20(5):655-67.

36. Krampera $M$, Cosmi $L$, Angeli $R$, Pasini A, Liotta F, Andreini $A$, et al. Role for interferon-gamma in the immunomodulatory activity of human bone marrow mesenchymal stem cells. Stem Cells. 2006;24(2):386-98.

37. Sheng $H$, Wang $Y$, Jin $Y$, Zhang $Q$, Zhang $Y$, Wang $L$, et al. A critical role of IFNgamma in priming MSC-mediated suppression of T cell proliferation through up-regulation of B7-H1. Cell Res. 2008;18(8):846-57.
38. Mougiakakos D, Jitschin R, Johansson CC, Okita R, Kiessling R, Le Blanc K The impact of inflammatory licensing on heme oxygenase-1-mediated induction of regulatory $T$ cells by human mesenchymal stem cells. Blood. 2011;117(18):4826-35.

39. Shi Y, Su J, Roberts Al, Shou P, Rabson AB, Ren G. How mesenchymal stem cells interact with tissue immune responses. Trends Immunol. 2012;33(3): 136-43.

40. Barrachina L, Remacha AR, Romero A, Vazquez FJ, Albareda J, Prades M, et al. Priming equine bone marrow-derived mesenchymal stem cells with proinflammatory cytokines: implications in immunomodulationimmunogenicity balance, cell viability, and differentiation potential. Stem Cells Dev. 2017;26(1):15-24.

41. Zucca E, Corsini E, Galbiati V, Lange-Consiglio A, Ferrucc F. Evaluation of amniotic mesenchymal cell derivatives on cytokine production in equine alveolar macrophages: an in vitro approach to lung inflammation. Stem Cell Res Ther 2016;7(1):137-37.

42. Wang L, Zhao Y, Liu Y, Akiyama K, Chen C, Qu C, et al. IFN-gamma and TNFalpha synergistically induce mesenchymal stem cell impairment and tumorigenesis via NFkappaB signaling. Stem Cells. 2013;31(7):1383-95.

43. Vizoso FJ, Eiro N, Cid S, Schneider J, Perez-Fernandez R. Mesenchymal stem cell secretome: toward cell-free therapeutic strategies in regenerative medicine. Int J Mol Sci. 2017;18(9):1852-75.

44. Bullon P, Cordero MD, Quiles JL, Morillo JM, del Carmen R-TM, Battino M. Mitochondrial dysfunction promoted by Porphyromonas gingivalis lipopolysaccharide as a possible link between cardiovascular disease and periodontitis. Free Radic Biol Med. 2011;50(10):1336-43.

45. Carrade DD, Lame MW, Kent MS, Clark KC, Walker NJ, Borjesson DL. Comparative analysis of the immunomodulatory properties of equine adultderived mesenchymal stem cells(). Cell Med. 2012;4(1):1-11.

46. Gaunt G, Ramin K. Immunological tolerance of the human fetus. Am J Perinatol. 2001:18(6):299-312.

\section{Publisher's Note}

Springer Nature remains neutral with regard to jurisdictional claims in published maps and institutional affiliations.

Ready to submit your research? Choose BMC and benefit from:

- fast, convenient online submission

- thorough peer review by experienced researchers in your field

- rapid publication on acceptance

- support for research data, including large and complex data types

- gold Open Access which fosters wider collaboration and increased citations

- maximum visibility for your research: over $100 \mathrm{M}$ website views per year

At $\mathrm{BMC}$, research is always in progress.

Learn more biomedcentral.com/submissions 